\title{
Age at Surgery and Outcomes of Undescended Testes at King Salman Armed Forces Hospital, Tabuk, Saudi Arabia
}

Mohammad S. Mohammad Alnoaiji ${ }^{1}$, Tahani N. Alrashidi ${ }^{2}$, Asmaa S. Ghmaird ${ }^{3}$, Sarah S. Alsalem ${ }^{2}$, Malak S. Alanazi ${ }^{4}$, Alanuad I. Albazei ${ }^{2}$, Maryam O. Alenzi ${ }^{2}$, Mastorah A. Aljuhani ${ }^{2}$, Rana S. Alotaibi ${ }^{2}$, Sara A. Alanazi $^{2}$, Aeshah M. Althomali ${ }^{2}$, Ahad M. Almohammadi ${ }^{4}$, Eid H. Alshahrani ${ }^{5}$

1. Paediatric Surgery, King Salman Armed Forces Hospitals, Tabouk, SAU 2. Pediatric Surgery, University of Tabuk, Tabuk, SAU 3. Pediatrics, University of Tabuk, Tabuk, SAU 4. Otolaryngology Head and Neck Surgery, University of Tabuk, Tabuk, SAU 5. Pediatric Surgery, University of Bisha, Bisha, SAU

Corresponding author: Mohammad S. Mohammad Alnoaiji, drmsnoaiji@gmail.com

\section{Abstract \\ Objective}

The aim of this study was to investigate the age at diagnosis and surgery of undescended testes and patients' outcomes.

\section{Methods}

This is a retrospective study that reviewed the files of patients who underwent orchidopexy at the King Salman Armed Forces Hospital (KSAFH), Tabuk, Saudi Arabia (SA), between January 1, 2015, and March 30, 2019. All children from birth until 13 years old who were admitted within the specified time frame and underwent orchidopexy were included in this study. The gathered data were analyzed through the Statistical Package for Social Sciences software (SPSS, version 23; SPSS Inc., Chicago, IL, USA).

\section{Results}

A total of 175 patients were included in this study. The rate of orchidopexy at our institution was $12.2 \%$. The median ages at diagnosis and surgery were 12 and 24 months, respectively. The median duration between diagnosis and surgery was eight months. The most common site of undescended testis was inguinal (80.6\%). Bilateral undescended testes were recorded in $24.6 \%$ of cases, and $25.7 \%$ of cases were impalpable. The size of the undescended testis was average in half the cases, small in $44.6 \%$ and atrophic in $6.4 \%$ of cases. Postoperative complications were reported in $4.0 \%$ of cases. Cox regression analysis revealed that the age at diagnosis was a significant risk factor affecting the time of surgery.

\section{Conclusion}

Received 11/18/2019

Review began 12/07/2019 Review ended 12/16/2019 Published 12/18/2019

\section{() Copyright 2019}

Mohammad Alnoaiji et al. This is an open access article distributed under the terms of the Creative Commons Attribution License CC-BY 3.0., which permits unrestricted use, distribution, and reproduction in any medium, provided the original author and source are credited.
The findings of this study revealed that most cases of undescended testes in Tabuk were operated beyond the age recommended by international guidelines. The age at diagnosis seems to significantly affect the time of surgery.

Categories: Pediatrics, Pediatric Surgery, Urology

Keywords: cryptorchidism, orchidopexy, undescended testis, age at surgery, outcomes

\section{Introduction}

Undescended testis (UDT) is a condition in which the testes do not descend to a normal position in the scrotum. It can be unilateral or bilateral. UDT is considered one of the major genital anomalies in young males [1]. Due to the continuous spontaneous descent of the testes, the prevalence by the age of three months decreases to $1 \%$ to $2 \%$ [2]. After 4 to 6 months, the UDT less likely descends spontaneously. Consequently, approximately one-third of UDT cases continue to exist. This condition requires surgical intervention with orchidopexy to fix the testes within scrotum [3]. The preferred age for orchiopexy is before the completion of the first year of life. Surgery during this specified period may have optimal outcomes in fertility and protection against testicular cancer [4]. Therefore, the earlier the patient undergoes surgery, the better the outcome is expected to be. Current guidelines recommend orchidopexy at 6 to 12 months old and no later than 18 months old [5-6]. There are no previous studies on the prevalence, age at surgery and outcomes of UDT in Tabuk. An assessment of the prevalence of UDT, as well as the age at diagnosis and surgery, can help estimate adherence to current guidelines and can prompt education campaigns for physicians and parents to highlight the problem of delayed treatment of UDT. Hence, the aim of this study was to investigate the prevalence of UDT, the age of affected boys at the time of surgery and the outcomes of surgery at the King Salman Armed Forces Hospital (KSAFH), Tabuk, Saudi Arabia (SA). 


\section{Materials And Methods}

This retrospective study involved the review of the hospital files of children with UDT who underwent orchidopexy operation at KSAFH, Tabuk, SA, between January 1, 2015, and March 30, 2019. The study was approved by the Research Ethics Committee of KSAFH, Tabuk, SA. KSAFH is a secondary hospital and considered one of the major hospitals in Tabuk City. It was established in 1979, with a bed capacity 900 beds. The study protected participants' privacy. Investigators were responsible for ensuring the security of the data. The participants' data were not used for any purpose outside this study. Personal data (e.g., name, contact info) were not entered in the datasheet software to protect the participants' privacy. Each subject was given a unique identifier code. Sample size was all children with UDT from birth until 13 years old who were admitted within the specified time frame and who underwent orchidopexy. Inclusion criteria were patients diagnosed undescended testis and patients younger than 13 years old at the time of orchidopexy. Exclusion criteria were patients older than 13 years old at the time of orchidopexy and incomplete data in hospital medical records. Patients' data were extracted from their medical records using their medical record number (MRN). Data were recorded into an Excel datasheet. The collected data included the following: a) age at diagnosis and surgery; b) year of surgery; c) the side of the UDT (right, left or bilateral); d) whether the testis was palpable on clinical examination; e) site of the UDT; f) type of surgical technique; and g) postoperative complications. Patients were divided into two groups according to the timing of the surgery: at/before 18 months of age (group 1) or later (group 2). Data management and analysis plan: The study variables were coded and analyzed using the Statistical Package for Social Sciences software (SPSS, version 23; SPSS Inc., Chicago, IL, USA). Categorical data were summarized as frequencies (numbers and percentages); associations between groups and categorical variables were tested using Pearson's chi-square tests, Fisher's exact tests, or Fisher-Freeman-Halton exact tests as appropriate. The distribution of numerical variables was tested using Shapiro-Wilk tests, and none of the variables were found to have a normal distribution. The data were then described using medians and interquartile ranges (expressed as 25 th to 75 th percentiles). Comparisons between the studied groups were done using Mann-Whitney U tests. Cox regression analysis was carried out to identify potential risk factors for delayed orchidopexy. Significance was adopted at $p<0.05$ for all tests.

\section{Results}

The hospital files of pediatric patients undergoing surgery at our institution were reviewed. The total number of pediatric surgeries performed during the study period was 1436 . Out of these patients, 175 underwent orchidopexy and met the inclusion and exclusion criteria of this study. Thus, the rate of orchidopexy at our institution was $12.2 \%$.

The temporal trend of orchidopexy operation at our institution was also analyzed. The highest number of orchidopexy operations was carried out in $2015(n=54)$, followed by $2017(n=41), 2016(n=39)$ and 2018 (n =35). The study included only three months of the year 2019; therefore, only six cases were included in our study from this year. The average number of orchidopexy operations per year was 40 . The rate of orchidopexies decreased in 2018 (8.4\%) compared to the rate in previous years (12.7\% to 14.7\%; Figure 1).

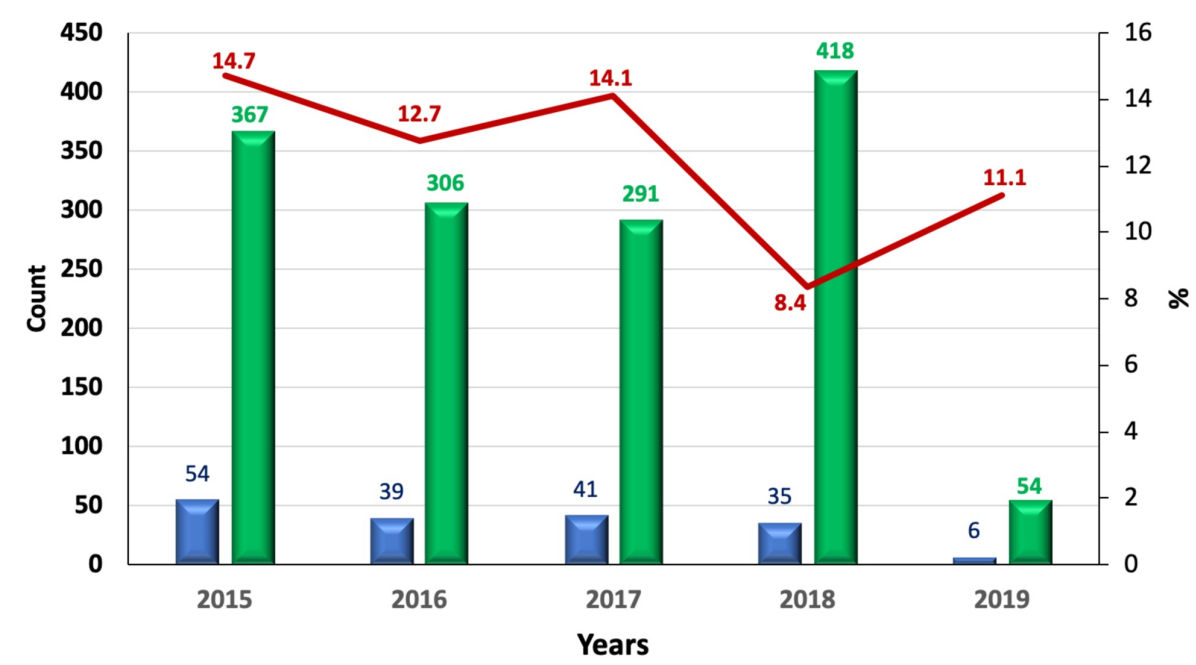

Ð orchidopexy $\quad$ Pediatric surgeries $\quad$ Rate of orchidopexy

FIGURE 1: Temporal trends in the rate of orchidopexy operations at our institution during the time of the study 


\section{Cureus}

Statistical analysis showed that the median age was 12 months at diagnosis and 24 months at surgery. The median duration between diagnosis and surgery was eight months. With respect to patients who underwent the two stages of the operation, the median age was 18 and 27 months at stages I and II, respectively. The median duration between the two stages was 12 months. Patients were divided into two groups according to their age at surgery. Only 66 cases out of 175 (37.7\%) underwent surgery during the recommended age period (at/before 18 months old). The median age at diagnosis was significantly higher in group 2 than in group 1 (23 months versus three months, $p<0.001$ ). However, there was no significant difference between the two groups with respect to the duration between diagnosis and surgery $(p=0.558)$, age at stage I $(p=0.057)$, age at stage II $(p=0.057)$ or the length of time between the two stages $(\mathrm{p}=0.629$; Table 1$)$.

\begin{tabular}{|c|c|c|c|c|c|}
\hline & & \multicolumn{3}{|l|}{ Groups } & \multirow{2}{*}{ p-value } \\
\hline & & $\begin{array}{l}\text { Total }(n= \\
175)\end{array}$ & $\begin{array}{l}\leq 18 \text { months }(\mathrm{n} \\
=66)\end{array}$ & $\begin{array}{l}>18 \text { months }(n= \\
109)\end{array}$ & \\
\hline \multirow{2}{*}{ Age at diagnosis (months) } & Range & $<1-156$ & $<1-15$ & $<1-156$ & $<0.001^{*}$ \\
\hline & $\begin{array}{l}\text { Median } \\
\text { (IQR) }\end{array}$ & $12(3-24)$ & $3(2-7)$ & $23(17-33)$ & \\
\hline \multirow{2}{*}{ Age at surgery (months) } & Range & $<1-156$ & $<1-18$ & 19-156 & $<0.001^{*}$ \\
\hline & $\begin{array}{l}\text { Median } \\
\text { (IQR) }\end{array}$ & $24(13-36)$ & $12(11-15)$ & $33(24-48)$ & \\
\hline \multirow{2}{*}{$\begin{array}{l}\text { Duration between diagnosis at pediatric surgery clinic and } \\
\text { surgery (months) }\end{array}$} & Range & $<1-72.0$ & $<1-17$ & $<1-72$ & 0.558 \\
\hline & $\begin{array}{l}\text { Median } \\
\text { (IQR) }\end{array}$ & $8(3-12)$ & $8(5-11)$ & $7(3-16)$ & \\
\hline \multirow{2}{*}{ Age at stage I (months) } & Range & $12-88$ & $12-18$ & $24-88$ & 0.057 \\
\hline & $\begin{array}{l}\text { Median } \\
\text { (IQR) }\end{array}$ & $18(14-25)$ & $16(13-18)$ & $25(24-88)$ & \\
\hline \multirow{2}{*}{ Age at stage II (months) } & Range & 24-102 & $24-27$ & $30-102$ & 0.057 \\
\hline & $\begin{array}{l}\text { Median } \\
\text { (IQR) }\end{array}$ & $27(24-48)$ & $25(24-27)$ & $48(30-102)$ & \\
\hline \multirow{2}{*}{ Duration between stage I and stage II (months) } & Range & $6-23$ & $7-13$ & $6-23$ & 0.629 \\
\hline & $\begin{array}{l}\text { Median } \\
\text { (IQR) }\end{array}$ & 12 (7-14) & $10(8-13)$ & $14(6-23)$ & \\
\hline
\end{tabular}

TABLE 1: Age at diagnosis, age at surgery, referral time and waitlist time in the studied patients IQR: interquartile range; *significant at $p<0.05$.

The median age of patients at diagnosis and at surgery was compared among the years studied, revealing no significant difference.The highest median age at diagnosis and at surgery were in 2019. The median age at surgery was substantially higher than the recommended age (before or at 18 months old; Figure 2). 


\section{Cureus}

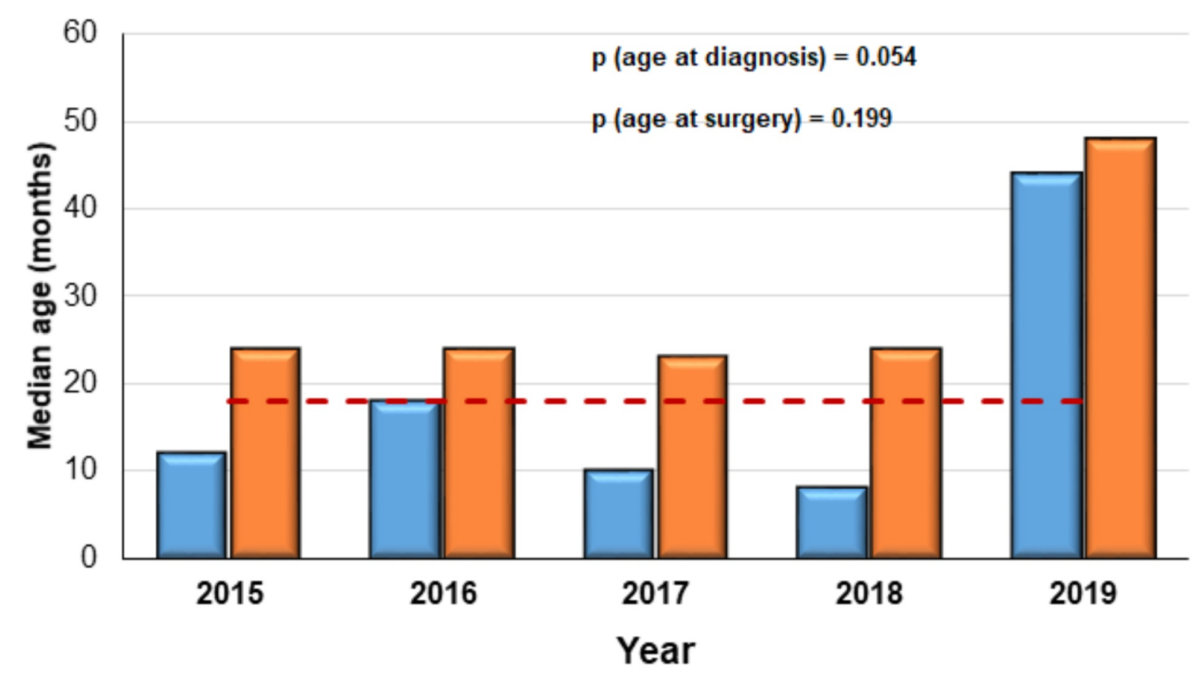

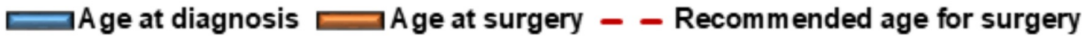

FIGURE 2: Median age at diagnosis and at surgery in the studied years. The dashed red line represents 18 months of age, which is the highest age limit according to clinical guidelines

Patients were divided into two groups according to their age at surgery. Only 66 cases out of 175 (37.7\%) underwent surgery during the recommended age period (at/before 18 months old). The median age at diagnosis was significantly higher in group 2 than in group 1 (23 months versus three months, $p<0.001$ ). However, there was no significant difference between the two groups with respect to the duration between diagnosis and surgery $(p=0.558)$, age at stage I ( $p=0.057)$, age at stage II $(p=0.057)$ or the length of time between the two stages $(p=0.629)$.

The most common site of UDT among the studied patients was inguinal (80.6\%). The testis was not seen in $7.4 \%$ of cases. Most cases were unilateral, while only $24.6 \%$ of cases were bilateral. In most cases, the UDTs were palpable $(73.1 \%)$, while only $25.7 \%$ of cases were impalpable. There was no significant difference between the studied groups with respect to the site or side of UDT ( $p>0.05)$. Significantly higher percentages of patients with early orchidopexies had unseen $(13.6 \%$ versus $3.7 \%, p=0.019)$ and impalpable ( $37.9 \%$ versus $18.3 \%, p=0.001$ ) UDTs than did patients with delayed operations (Table 2 ). 


\section{Cureus}

\begin{tabular}{|c|c|c|c|c|c|c|c|c|}
\hline & & \multicolumn{6}{|c|}{ Groups } & \multirow{3}{*}{$\begin{array}{l}\begin{array}{l}\mathrm{p}- \\
\text { value }\end{array} \\
1.000\end{array}$} \\
\hline & & \multicolumn{2}{|c|}{$\begin{array}{l}\text { Total }(n= \\
175)\end{array}$} & \multicolumn{2}{|c|}{$\begin{array}{l}\leq 18 \text { months }(\mathrm{n}= \\
66)\end{array}$} & \multicolumn{2}{|c|}{$\begin{array}{l}>18 \text { months }(n= \\
109)\end{array}$} & \\
\hline \multirow{5}{*}{ Site of UDT } & Intra-abdominal & 10 & $5.7 \%$ & 4 & $6.1 \%$ & 6 & $5.5 \%$ & \\
\hline & Inguinal & 141 & $80.6 \%$ & 49 & $74.2 \%$ & 92 & $84.4 \%$ & 0.100 \\
\hline & Upper scrotum & 12 & $6.9 \%$ & 5 & $7.6 \%$ & 7 & $6.4 \%$ & 0.766 \\
\hline & Ectopic & 2 & $1.1 \%$ & 0 & $0.0 \%$ & 2 & $1.8 \%$ & 0.527 \\
\hline & Not seen & 13 & $7.4 \%$ & 9 & $13.6 \%$ & 4 & $3.1 \%$ & $0.019^{\star}$ \\
\hline \multirow{3}{*}{ Side of testis } & Bilateral & 43 & $24.6 \%$ & 13 & $19 . / \%$ & 30 & $27.5 \%$ & \multirow{3}{*}{0.401} \\
\hline & Unilateral, left & 75 & $42.9 \%$ & 32 & $48.5 \%$ & 43 & $39.4 \%$ & \\
\hline & Unilateral, right & 57 & $32.6 \%$ & 21 & $31.8 \%$ & 36 & $33.0 \%$ & \\
\hline \multirow{3}{*}{$\begin{array}{l}\text { In clinical examination, testis } \\
\text { was }\end{array}$} & Impalpable & 45 & $25.7 \%$ & 25 & $37.9 \%$ & 20 & $18.3 \%$ & \multirow{3}{*}{$0.001^{*}$} \\
\hline & Palpable & 128 & $73.1 \%$ & 39 & $59.1 \%$ & 89 & $81.7 \%$ & \\
\hline & $\begin{array}{l}\text { One palpable and the other } \\
\text { impalpable }\end{array}$ & 2 & $1.1 \%$ & 2 & $3.0 \%$ & 0 & $0.0 \%$ & \\
\hline
\end{tabular}

\section{TABLE 2: Year of surgery and clinical findings in the studied patients}

*Significant at $p<0.05$

Approximately one-quarter of cases had an associated operation at the same time as the orchidopexy, the most common of which was circumcision, followed by herniotomy in 16 cases $(9.1 \%)$ and hydrocelectomy in three cases $(1.7 \%)$.

With respect to the surgical approach used, the majority of cases were operated upon using then open technique (85.7\%). The open technique was used in all palpable UDTs, while the laparoscopic technique was used for impalpable testes. The size of the UDT was average in nearly half the cases, small in $44.6 \%$ and atrophic/vanishing in $6.4 \%$ of cases. No significant associations were found between the time of surgery and the surgical approach, the size of UDTs or associated operations (Table 3). 


\section{Cureus}

\begin{tabular}{|c|c|c|c|c|c|c|c|c|}
\hline & & \multicolumn{6}{|c|}{ Groups } & \multirow{3}{*}{$\begin{array}{l}\begin{array}{l}\mathrm{p}- \\
\text { value }\end{array} \\
0.826\end{array}$} \\
\hline & & \multicolumn{2}{|c|}{$\begin{array}{l}\text { Total }(n= \\
\text { 175) }\end{array}$} & \multicolumn{2}{|c|}{$\begin{array}{l}\leq 18 \text { months }(n= \\
66)\end{array}$} & \multicolumn{2}{|c|}{$\begin{array}{l}>18 \text { months }(\mathrm{n}= \\
109)\end{array}$} & \\
\hline \multirow{3}{*}{ Surgery } & Open & 150 & $85.7 \%$ & 56 & $84.8 \%$ & 94 & $86.2 \%$ & \\
\hline & Laparoscopic stage I & 22 & $12.6 \%$ & 8 & $12.1 \%$ & 14 & $12.8 \%$ & 0.889 \\
\hline & Laparoscopic stage II & 7 & $4.0 \%$ & 5 & $7.6 \%$ & 2 & $1.8 \%$ & 0.105 \\
\hline \multirow{4}{*}{ Intraoperative findings } & Average size & 86 & $49.1 \%$ & 32 & $48.5 \%$ & 54 & $49.5 \%$ & 0.875 \\
\hline & Small size & 78 & $44.6 \%$ & 30 & $45.5 \%$ & 48 & $44.0 \%$ & 0.869 \\
\hline & Vanishing atrophic & 11 & $6.4 \%$ & 3 & $4.6 \%$ & 8 & $7.5 \%$ & 0.538 \\
\hline & $N / R$ & 3 & $1.7 \%$ & 1 & $1.5 \%$ & 2 & $1.8 \%$ & \\
\hline \multicolumn{2}{|c|}{ Other associated operation at the same time } & 46 & $26.3 \%$ & 21 & $31.8 \%$ & 25 & $22.9 \%$ & 0.196 \\
\hline \multirow{7}{*}{$\begin{array}{l}\text { Type of associated operation at the } \\
\text { same time }\end{array}$} & Circumcision & 27 & $15.4 \%$ & 14 & $21.2 \%$ & 13 & $11.9 \%$ & 0.099 \\
\hline & Herniotomy & 16 & $9.1 \%$ & 5 & $7.6 \%$ & 11 & $10.1 \%$ & 0.576 \\
\hline & Hydrocelectomy & 3 & $1.7 \%$ & 1 & $1.5 \%$ & 2 & $1.8 \%$ & 1.000 \\
\hline & Meatotomy & 2 & $1.1 \%$ & 1 & $1.5 \%$ & 1 & $0.9 \%$ & 1.000 \\
\hline & Orchidectomy & 1 & $0.6 \%$ & 1 & $1.5 \%$ & 0 & $0.0 \%$ & 0.377 \\
\hline & $\begin{array}{l}\text { Subcoronal hypospadias } \\
\text { repair }\end{array}$ & 1 & $0.6 \%$ & 0 & $0.0 \%$ & 1 & $0.9 \%$ & 1.000 \\
\hline & Frenotomy & 1 & $0.6 \%$ & 0 & $0.0 \%$ & 1 & $0.9 \%$ & 1.000 \\
\hline
\end{tabular}

\section{TABLE 3: Type and findings of surgery in the studied patients}

N/R, not recorded

The surgeries were eventless in the majority of cases, as complications were reported only in $4.0 \%$. Wound infection was the most commonly recorded complication (three cases, $1.7 \%$ ). No significant associations were found between the time of surgery and the occurrence or type of complications (Table 4). 


\section{Cureus}

\begin{tabular}{|c|c|c|c|c|c|c|c|c|}
\hline & & \multicolumn{6}{|c|}{ Groups } & \multirow{2}{*}{$p$-value } \\
\hline & & \multicolumn{2}{|c|}{ Total $(n=175)$} & \multicolumn{2}{|c|}{$\leq 18$ months $(n=66)$} & \multicolumn{2}{|c|}{$>18$ months $(n=109)$} & \\
\hline \multirow{3}{*}{ Complications } & Absent & 166 & $94.9 \%$ & 65 & $98.5 \%$ & 101 & $92.7 \%$ & \multirow{3}{*}{0.254} \\
\hline & Present & 7 & $4.0 \%$ & 1 & $1.5 \%$ & 6 & $5.5 \%$ & \\
\hline & $N / R$ & 2 & $1.1 \%$ & 0 & $0.0 \%$ & 2 & $1.8 \%$ & \\
\hline \multirow{4}{*}{ Reported complications } & Wound infection & 3 & $1.7 \%$ & 1 & $1.5 \%$ & 2 & $1.9 \%$ & 1.000 \\
\hline & Inguinal hernia & 2 & $1.2 \%$ & 0 & $0.0 \%$ & 2 & $1.9 \%$ & 0.525 \\
\hline & Hydrocele & 1 & $0.6 \%$ & 0 & $0.0 \%$ & 1 & $0.9 \%$ & 1.000 \\
\hline & Testicular retraction & 1 & $0.6 \%$ & 0 & $0.0 \%$ & 1 & $0.9 \%$ & 1.000 \\
\hline
\end{tabular}

\section{TABLE 4: Postoperative complications in the studied patients}

$\mathrm{N} / \mathrm{R}$, not recorded

Cox regression analysis was conducted to identify potential risk factors for delayed orchidopexy. The included variables in the analysis were age at diagnosis, site and side of the UDT and palpability of the testis on clinical examination. We found that age at diagnosis was the only significant risk factor that affected the time of surgery (HR $=1.015, p<0.001$; Table 5).

\begin{tabular}{|c|c|c|c|c|c|c|}
\hline & & \multirow{2}{*}{ Wald } & \multirow{2}{*}{ p-value } & \multirow{2}{*}{ HR } & \multicolumn{2}{|c|}{$95.0 \% \mathrm{Cl}$ for $\mathrm{HR}$} \\
\hline & & & & & Lower & Upper \\
\hline \multicolumn{2}{|c|}{ Age at diagnosis (months) } & 23.647 & $<0.001^{*}$ & 1.015 & 1.009 & 1.021 \\
\hline \multirow{5}{*}{ Site of UDT } & Intra-abdominal & 0.003 & 0.954 & 0.949 & 0.162 & 5.579 \\
\hline & Inguinal & 0.000 & 0.984 & 1.019 & 0.163 & 6.356 \\
\hline & upper scrotum & 0.007 & 0.932 & 0.918 & 0.127 & 6.638 \\
\hline & Ectopic & 1.370 & 0.242 & 2.692 & 0.513 & 14.135 \\
\hline & Not seen & 0.991 & 0.320 & 0.336 & 0.039 & 2.880 \\
\hline \multicolumn{2}{|c|}{ Side of testis (bilateral) } & 1.257 & 0.262 & 1.297 & 0.823 & 2.043 \\
\hline \multicolumn{2}{|c|}{ Impalpable UDT } & 0.239 & 0.625 & 0.843 & 0.424 & 1.674 \\
\hline
\end{tabular}

\section{TABLE 5: Cox regression to assess risk factors for delayed orchidopexy}

HR: hazard ratio; Cl: confidence interval; *significant at $p<0.0$

\section{Discussion}

The present study included 175 patients who underwent orchidopexy from January 1, 2015 to March 30, 2019, with an average number of 40 cases operated annually. Similar rates were recorded from Saudi Arabia. An audit by Shareef et al. at King Fahad Hospital, Al Baha reported that 116 patients underwent orchidopexy over the course of three years, with an average of 39 cases per year [7].

Higher and lower rates of orchidopexies were reported by other studies. An audit conducted by Alsaywid in Sydney, Australia reported that 169 orchidopexies were performed within a period of two years [8]. Much lower rates were reported by other studies, such as the one conducted in Pakistan reporting 159 cases in 10 years [9].

The orchidopexy operation rate at our institution showed an unexplained decrease in 2018 (8.4\%) compared to the previous years $(12.7-14.7 \%)$. This decrease may be attributed to either a true decline in the incidence 
of UDT in Tabuk or a failure in the diagnosis and management of the disease.

Studies from other countries have shown varying temporal trends of the annual rate of orchidopexy. Springer et al. studied orchidopexies performed in Austria between 1993 and 2009 and found the total rate of orchidopexy to rise continuously throughout the study period [10]. However, an Australian study demonstrated a true decline in the number of orchidopexies from 1999 to 2006 in Victoria [11]. The authors attributed this decline to changes in screening practices in the state of Victoria. We did not find similar studies that analyzed temporal trends in orchidopexies during our study period.

Surgery is a crucial treatment for UDT. Earlier surgery can prevent infertility and decrease the development of testicular cancer [4].

The recommended age of a patient at orchidopexy has changed considerably over the past several years. The guidelines issued by the American Urological Association, the American Academy of Pediatrics and the European Association of Urology/European Society for Pediatric Urology recommended that treatment should be started at the age of six months and be completed by the age of 12 months or, at the latest, 18 months $[5,12-13]$.

In the present study, the median age at surgery was 24 months, with only $37.7 \%$ of cases undergoing orchidopexy during the recommended age period. Interestingly, this deviation from the recommendations of international guidelines persisted throughout the study, as a high median age at surgery was detected each year. The median duration between diagnosis and surgery was also relatively long (eight months).

Several studies from around the world have reported that the average age at orchidopexy was, unfortunately, higher than the age recommended by the guidelines. However, the reported ages at diagnosis and at surgeryas well as the wait time for the operation-varied widely across these studies.

Locally, Neel studied orchidopexies in two hospitals in Riyadh, Saudi Arabia, and found that $45 \%$ of patients were diagnosed with UDT after one year of age [14]. Sharif et al. analyzed cases at King Fahad Hospital, Al Baha, SA, from 2011 to 2013 . They reported that the mean age at surgery was almost three years, with $41.3 \%$ of boys undergoing orchidopexy being older than two years old [7]. Alsowayan and his colleagues conducted a study in the King Fahad Hospital, Al Khobar, Eastern Province, SA. They demonstrated that the median ages at diagnosis and at surgery were 13.7 months and 25 months, respectively, with an average wait time for the operation of 4.8 months [15].

Internationally, Schneuer et al. conducted a study in New South Wales, Australia, and reported the median age of orchidopexy to be 16.6 months [1]. Another Australian study in Victoria reported a much older age at the time of surgery, as approximately $55 \%$ were at least five years old [16]. Mallikarjuna et al. studied 30 cases at Chigateri General Hospital and Bapuji Hospital, Davangere, India. Their results demonstrated that $44.4 \%$ of boys presented for treatment after the age of three years [17]. A recent study conducted in the USA found that approximately $70 \%$ of boys with UDT underwent orchidopexy at least six months later than the recommended age [18].

However, a study by Alsaywid in Sydney, Australia, reported more favorable results, as only one-quarter of operated patients were older than 2 years of age, with the median age at surgery being 11 months [8]. Favorable results were also reported by Bajaj and Upadhyay, who conducted a retrospective study at Starship Children's Hospital, Auckland, New Zealand. Their results showed that the median period between the clinic visit and the operation was 2.95 months, and the children's median age at the time of surgery was 12.63 months. Moreover, $66 \%$ of cases had surgery before 18 months of age [19].

In our series of patients, cases of UDT were mostly unilateral (75.4\%), and only $24.6 \%$ were bilateral. The most common side in unilateral UDT was the left ( $42.9 \%$ versus $32.6 \%$ on the right side). This finding contradicted the results of Mallikarjuna et al. and Ashley et al. who reported the most common side to be the right. $[17,20]$

The most common site of UDT was inguinal in our patients, followed by suprascrotal and intra-abdominal, which is consistent with the results found by Alsaywid and Mallikarjuna et al. [13,17].

In the present study, the UDT was impalpable in approximately one-quarter of the cases. This finding is in accordance with the findings of another study, which found nearly one-third of cases to have impalpable testes [8]. In another study, however, a much lower percentage of UDTs (10\%) were impalpable [7].

Testes can be impalpable due to their site (intra-abdominal, intracanalicular, ectopic), size (atrophic) or congenital dysgenesis or agenesis.

Most cases in this study (85.7\%) were operated using the open surgical technique, while the laparoscopic technique was used only in $14.3 \%$ of cases. Sharif et al. reported the use of laparoscopy in only $9.65 \%$ of 
their cases [7]. The open approach is usually used for palpable testes, while laparoscopic surgery is usually reserved for impalpable UDTs [21].

We found that UDTs of average size constituted $49.1 \%$ of our cases, while $44.6 \%$ of UDTs were small and $6.4 \%$ were atrophic. The rate of atrophic UDTs reported in previous studies varied from $3.4 \%$ to $11.8 \%[7-8]$.

Complications were recorded in seven cases (4.0\%) in our series. Similar rates of complications were reported by previous studies, ranging from $4.2 \%$ to $6.8 \%[7-8]$.

With respect to the causes of delayed orchidopexy for UDTs, we were not able to investigate all potential causes (such as educational level, socioeconomic status of the family, presence of medical insurance, presence of comorbidities and physicians' experience) due to the retrospective nature of the study. However, it was evident from our results that the age at diagnosis affected significantly the time of surgery. Moreover, the wait time from diagnosis to surgery was relatively long. These factors were also detected by previous studies. Chen et al. in Taiwan showed that the age of patients at diagnosis, the number of clinic visits prior to surgery, the patient's residence, the age of the physician making the initial diagnosis, and the age of the surgeon performing the surgery were significantly associated with delayed surgery [22]. Studies by Alsowayan et al. and Alhazmi et al. also suggested that delayed diagnosis and prolonged referral and wait times are important factors that contribute to delayed orchidopexy in Saudi Arabia $[15,23]$.

Undescended testes can be diagnosed at birth in most cases. The diagnosis depends on the physician's experience and the examination setup [24]. The delay in diagnosis and referral is attributed mainly to physicians' deficient knowledge of UDTs and poor attitude. A survey in the United States found that only $30 \%$ of pediatricians and $14 \%$ of general practitioners recommended orchidopexy before the first year of life [25]. Another survey in the United States reported that $20 \%$ of the physicians did not refer children with UDT until puberty [26].

Pediatricians and family doctors have a duty to screen neonates for congenital anomalies, refer the cases to specialists and counsel the parents on the complications of delayed intervention. Consequently, there is a need to establish a protocol for newborn examination in which pediatricians screen for congenital anomalies and then refer patients to qualified, experienced pediatric surgeons. Physician training can improve their knowledge and attitude with respect to the timely diagnosis and referral of children with UDTs.

\section{Conclusions}

In conclusion, in our study, the majority of cases underwent orchidopexy after the recommended age by international guidelines. The age at diagnosis seems to significantly affect the age at surgery. Educational programs that target general practitioners, pediatricians and parents are recommended to raise awareness of the importance of the early diagnosis and timed surgical management of undescended testes.

\section{Additional Information \\ Disclosures}

Human subjects: Consent was obtained by all participants in this study. Research ethics committee king Salman Armed Forces Hospital, Tabuk, Saudi Arabia issued approval KSAFH-REC-2019-281. Research ethics committee approval at King Salman Armed Forces Hospital, Tabuk, Saudi Arabia. name of principle investigator : Mohammad Mohammad alnoaiji. ethics ID number : KSAFH-REC-2019-281 Tittle : Prevalence, age at surgery and outcomes of Undescended Testes in King Salman Armed Forces Hospital, Tabuk the above-noted proposal has been submitted for expedited ethics review and found to be ethically acceptable. Animal subjects: All authors have confirmed that this study did not involve animal subjects or tissue. Conflicts of interest: In compliance with the ICMJE uniform disclosure form, all authors declare the following: Payment/services info: All authors have declared that no financial support was received from any organization for the submitted work. Financial relationships: All authors have declared that they have no financial relationships at present or within the previous three years with any organizations that might have an interest in the submitted work. Other relationships: All authors have declared that there are no other relationships or activities that could appear to have influenced the submitted work.

\section{References}

1. Schneuer FJ, Holland AJA, Pereira G, Jamieson S, Bower C, Nassar N: Age at surgery and outcomes of an undescended testis. Pediatrics. 2016, 137:20152768. 10.1542/peds.2015-2768

2. Alagaratnam S, Nathaniel C, Cuckow P, et al.: Testicular outcome following laparoscopic second stage Fowler-Stephens orchidopexy. J Pediatr Urol. 2014, 10:186-192. 10.1016/j.jpurol.2013.08.005

3. Vikraman J, Hutson JM, Li R, Thorup J: The undescended testis: clinical management and scientific advances. Semin Pediatr Surg. 2016, 25:241-248. 10.1053/j.sempedsurg.2016.05.007

4. Chan E, Wayne C, Nasr A: Ideal timing of orchiopexy: a systematic review. Pediatr Surg Int. 2014, 30:87-97. 10.1007/s00383-013-3429-y

5. Kolon TF, Herndon CD, Baker LA, et al.: Evaluation and treatment of cryptorchidism: AUA guideline . J Urol. 2014, 192:337-345. 10.1016/j.juro.2014.05.005 
6. Radmayr C, Dogan HS, Hoebeke P, et. al.: Management of undescended testes: European Association of Urology/European Society for Paediatric Urology guidelines. J Pediatr Urol. 2017, 13:550.

10.1016/j.jpurol.2016.07.014

7. Sharif M, Hafiz ASB, Bashir T, Elsiddig IE, Ibrahim M: A three years audit of surgical management of undescended testis - Experience at King Fahad Hospital, al Baha, KSA. PJMHS. 2017, 11:829-831.

8. Alsaywid B: Surgical management of undescended testis: a two-year practice audit . Webmed Central Paediatric Surgery. 2013, 2:1-13. Accessed: December 18, 2019:

https://www.webmedcentral.com/wmcpdf/Article_WMC004027.pdf.

9. Saeed A, Nawaz M, Griffin S: An audit of undescended testes treated at DHQ Hospital . Abbottabad Med Forum Month. 2011, 22:7. 10

10. Springer A, Subramaniam R, Krall C, Fülöp G: Orchidopexy patterns in Austria from 1993 to 2009. J. Pediatr. Urol.. 2013, 9:535-541. https://doi.org/10.1016/j.jpurol.2012.08.003

11. Bonney T, Southwell B, Donnath S, Newgreen D, Hutson J: Orchidopexy trends in the paediatric population of Victoria, 1999-2006. J Pediatr Surg. 2009, 44:427-431. 10.1016/j.jpedsurg.2008.10.099

12. Kolon TF: Guideline discusses diagnosis, treatment of cryptorchidism. AAP News. 2014, 35:https://doi.org/10.1542/aapnews.2014356-12a

13. Radmayr C, Dogan HS, Hoebeke P, et al.: Management of undescended testes: European Association of Urology/European Society for Paediatric Urology Guidelines. J Pediatr Urol. 2016, 12:335-343. 10.1016/j.jpurol.2016.07.014

14. Neel KF: Orchidopexy for undescended testis among Saudi children: is it conducted at optimum age? . Curr Pediatr Res. 2010, 14:39-41.

15. Alsowayan OS, Basalelah JH, Alzahrani AM, Alshaibani AM, Alalyani NS, Alsubiani TA, AlMadi MK: Age at presentation of undescended testicles: a single-center study in Saudi Arabia. Ann Saudi Med. 2018, 38:137139. 10.5144/0256-4947.2018.137

16. Bruijnen CJ, Vogels HD, Beasley SW: Age at orchidopexy as an indicator of the quality of regional child health services. J Paediatr Child Health. 2012, 48:556-559. 10.1111/j.1440-1754.2011.02202.x

17. Mallikarjuna M, Dhotre M, Shanmukhappa S: A study on surgical management of undescended testis . Int J Res Med Sci. 2018. 2018, 6:6. http://dx.doi.org/10.18203/2320-6012.ijrms20183653

18. Williams K, Baumann L, Shah A, Abdullah F, Johnson EK, Oyetunji TA: Age at orchiopexy for undescended testis in the United States. J Pediatr Surg. 2018, 53:86-89. 10.1016/j.jpedsurg.2017.10.020

19. Bajaj M and Upadhyay V: Age at referral for undescended testes: has anything changed in a decade? . N Z Med J. 2017, 130:45-49.

20. Ashley RA, Barthold JS, Kolon TF: Cryptorchidism: pathogenesis, diagnosis, treatment and prognosis . Urol Clin North Am. 2010, 37:183-193. 10.1016/j.ucl.2010.03.002

21. Abaci A, Catli G, Anik A, Bober E: Epidemiology, classification and management of undescended testes: does medication have value in its treatment?. J Clin Res Pediatr Endocrinol. 2013, 5:65-72. 10.4274/Jcrpe.883

22. Chen YF, Huang WY, Huang KH, Hsieh JT, Lan CF, Chang HC: Factors related to the time to cryptorchidism surgery--a nationwide, population-based study in Taiwan. J Formos Med Assoc. 2014, 113:915-920. https://doi.org/10.1016/j.jfma.2013.06.001

23. Alhazmi H, Junejo NN, Albeaiti M, Alshammari A, Aljallad H, Almathami A, Vallascianib S: Timing of orchidopexy at a tertiary center in Saudi Arabia: reasons for late surgery. Ann Saudi Med. 2018, 38:284-287. 10.5144/0256-4947.2018.284

24. Virtanen HE, Bjerknes R, Cortes D, et al.: Cryptorchidism: classification, prevalence and long-term consequences. Acta Paediatr. 2007, 96:611-616. 10.1111/j.1651-2227.2007.00241.x

25. Steckler RE, Zaontz MR, Skoog SJ, Rushton HG: Cryptorchidism, pediatricians, and family practitioners: patterns of practice and referral. J Pediatr. 1995, 127:948-951. 10.1016/s0022-3476(95)70034-X

26. Shnorhavorian M, Jacobs MA, Stearns G, Mingin G, Koyle MA: Practice variation and clinical confusion regarding undescended testes and retractile testes among primary care respondents: a multi-regional survey study in the United States. Pediatr Surg Int. 2012, 28:635-639. 10.1007/s00383-012-3085-7 